Supplement of

\title{
A machine-learning-guided adaptive algorithm to reduce the computa- tional cost of integrating kinetics in global atmospheric chemistry models: application to GEOS-Chem versions 12.0.0 and 12.9.1
}

Lu Shen et al.

Correspondence to: Lu Shen (lshen@pku.edu.cn)

The copyright of individual parts of the supplement might differ from the article licence. 


\section{Supplementary materials}

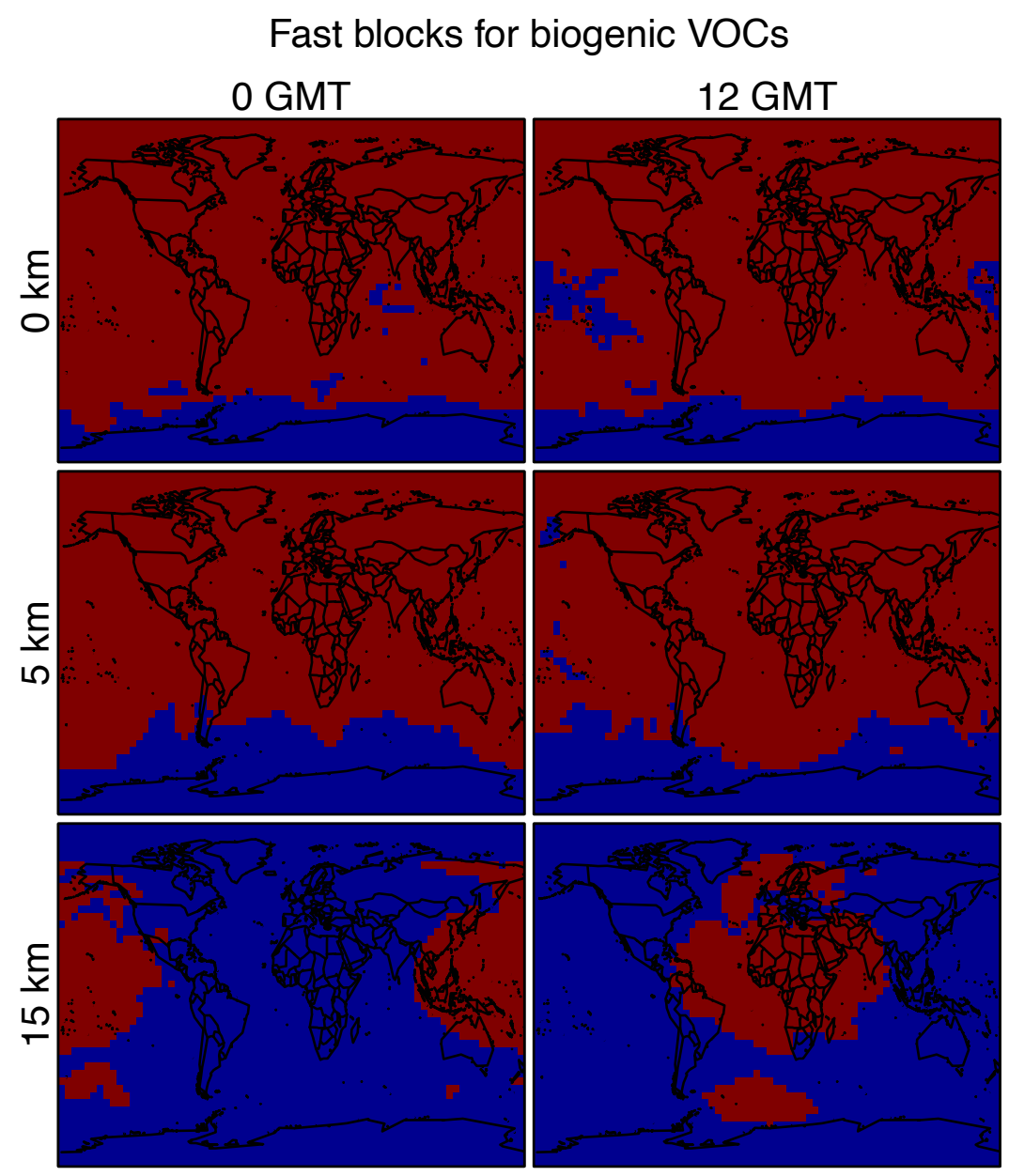

3 Fig. S1. Locations of anthropogenic blocks (block 5-7) that need to be solved as fast (red color). If any of block 5-7 is fast, the gridbox will be labeled as red. Results are shown on August 12013 at 0 and 12 GMT using a threshold $\delta$ of 500 molecules $\mathrm{cm}^{-}$ ${ }^{3} \mathrm{~s}^{-1}$ to define the fast and slow species, and a lifetime of 10 days to define the short-lived and long-lived species. 


\section{Fast blocks for biogenic VOCs}

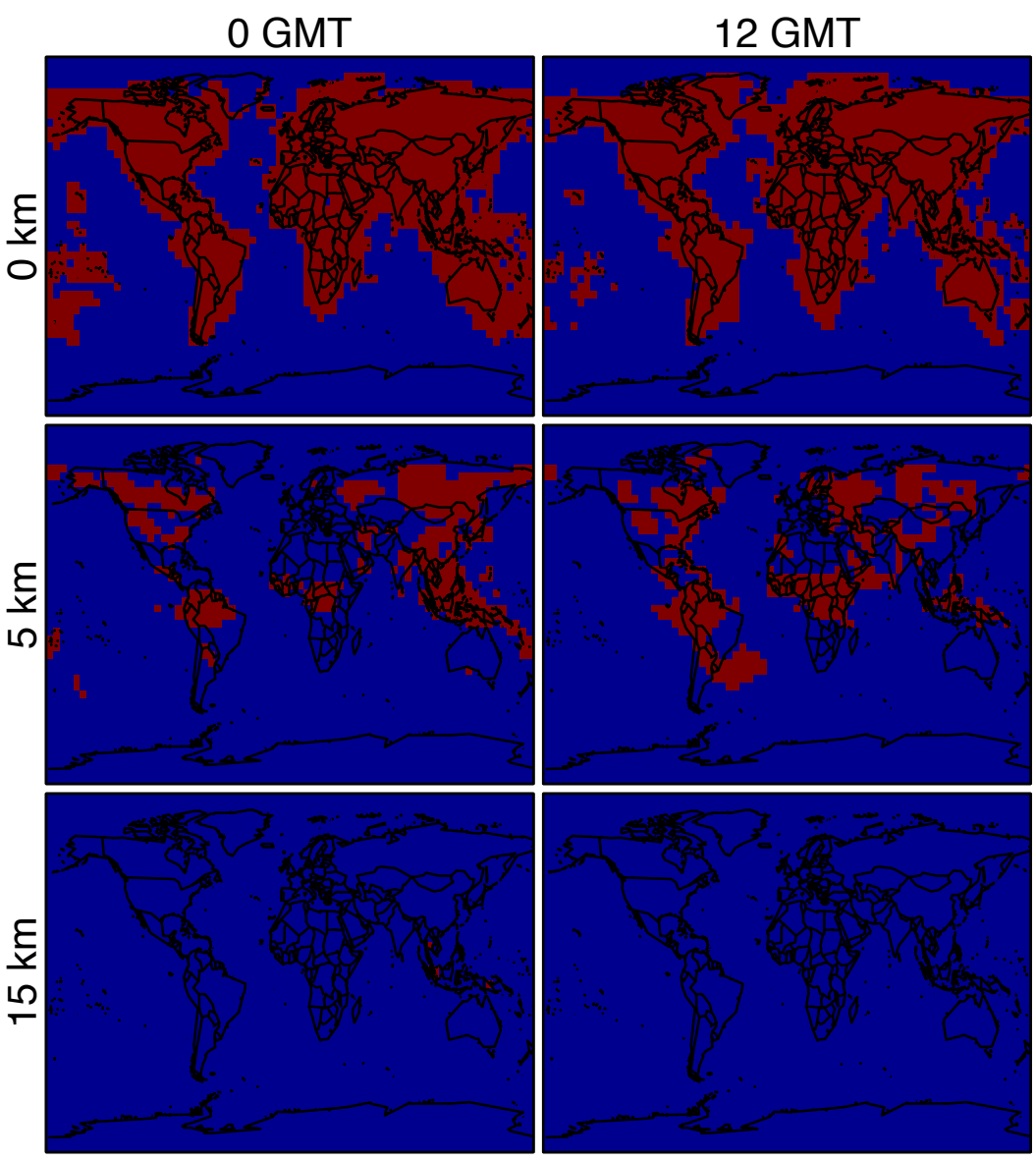

9 Fig. S2. Locations of biogenic blocks (block 8-11) that needs to be solved as fast (red). If any of block 8-11 is fast, the gridbox 10 will be labeled as red. Results are shown on August 12013 at 0 and 12 GMT using a threshold $\delta$ of 500 molecules cm${ }^{-3} \mathrm{~s}^{-1}$ to 11 define the fast and slow species, and a lifetime of 10 days to define the short-lived and long-lived species. 


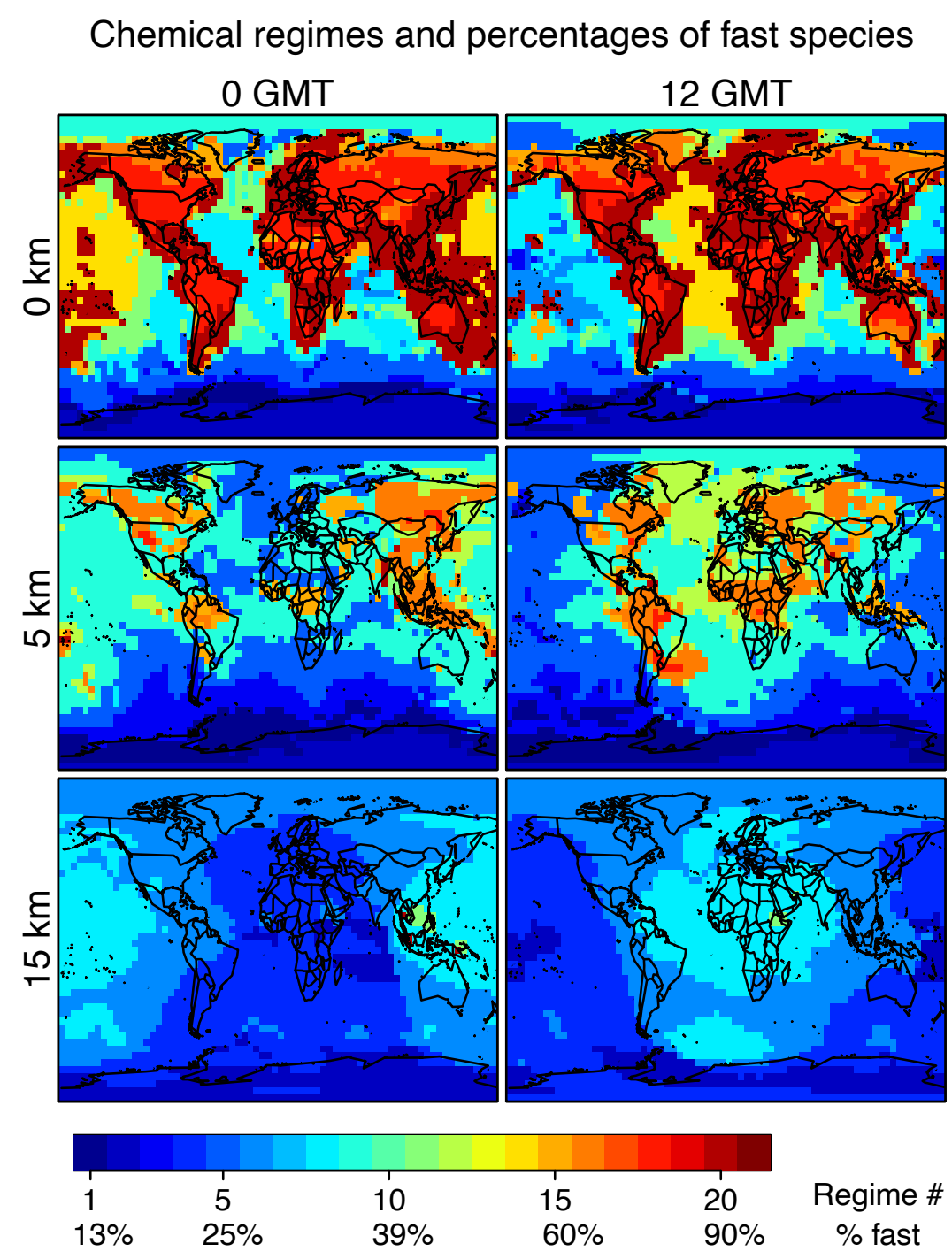

Fig. S3. Chemical mechanism complexity used in the adaptive chemical mechanism in different regions of the atmosphere. The Figure identifies the submechanism from Fig. 5 needed to simulate a given GEOS-Chem gridbox on August 12013 at 0 and 12 GMT. The percentage of species treated as fast in that chemical regime is shown on the colorbar and more details are in Table 1. The $21^{\text {st }}$ chemical regime is the full chemical mechanism. We use a threshold $\delta$ of 500 molecules $\mathrm{cm}^{-3} \mathrm{~s}^{-1}$ to partition the fast and slow species. 


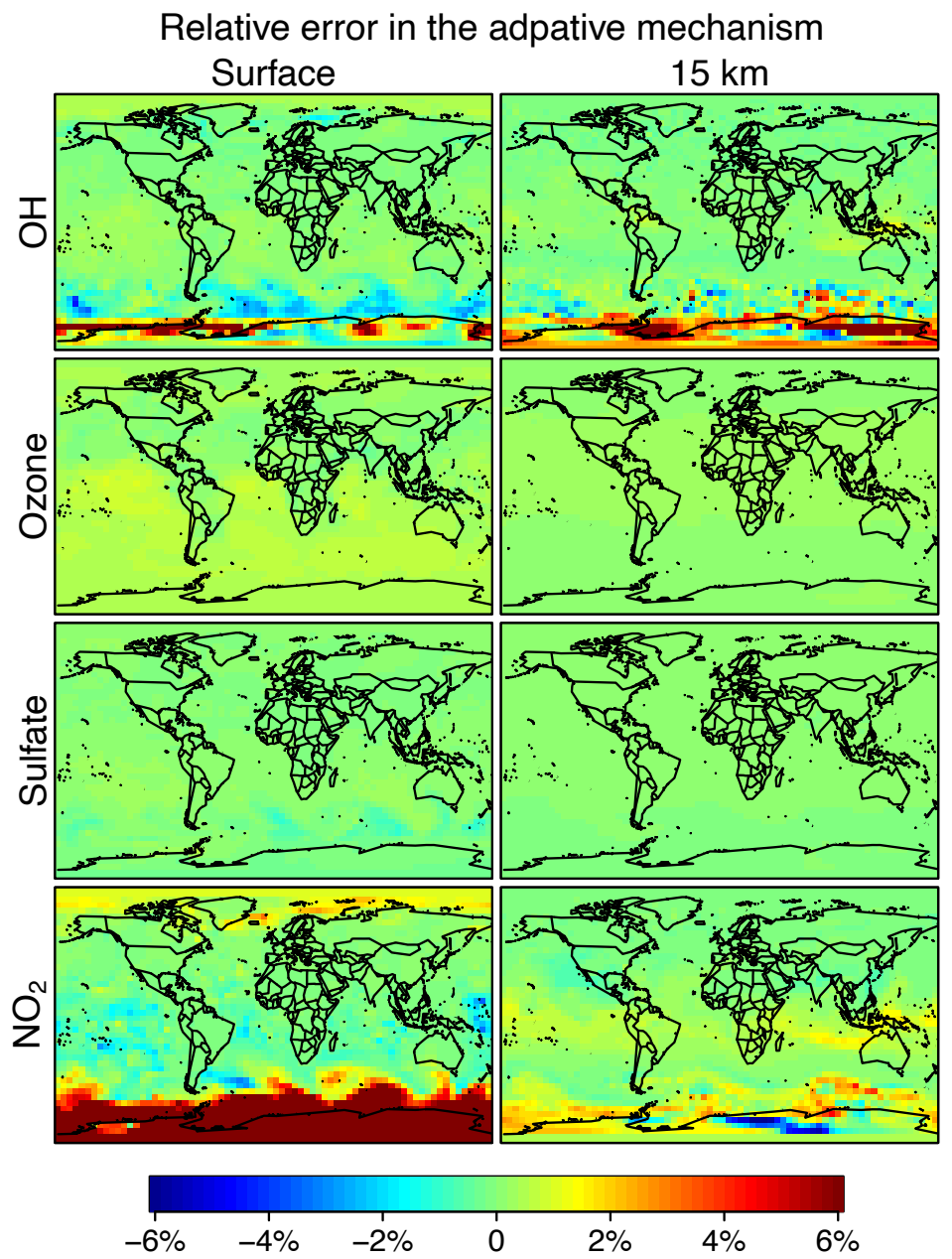

19 Fig. S4. Relative error from the adaptive mechanism reduction method after three years of simulation in the GEOS-Chem global 20 3-D model for tropospheric-stratospheric chemistry. The figure shows relative differences of 24-h average OH, ozone, sulfate 21 and $\mathrm{NO}_{2}$ concentrations relative to the full-chemistry simulation on the last day of the three-year simulation. The calculation removes slow ( $\mathrm{P}$ and $\mathrm{L}<1500$ molecules $\mathrm{cm}^{-3} \mathrm{~s}^{-1}$ ) and slow reactions (rate $<10$ molecules $\mathrm{cm}^{-3} \mathrm{~s}^{-1}$ ). The number of blocks $(N)$ is 13 and the number of chemical regimes $(M)$ is 20 . 
Relative differences of atmospheric masses for different species categories

(a) Boundary layer

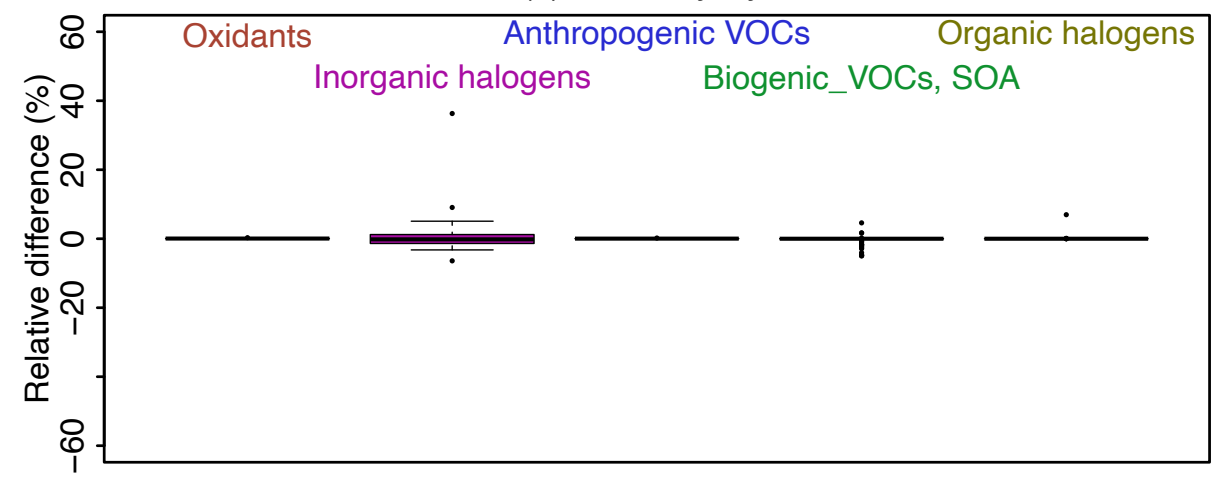

(b) Free troposphere

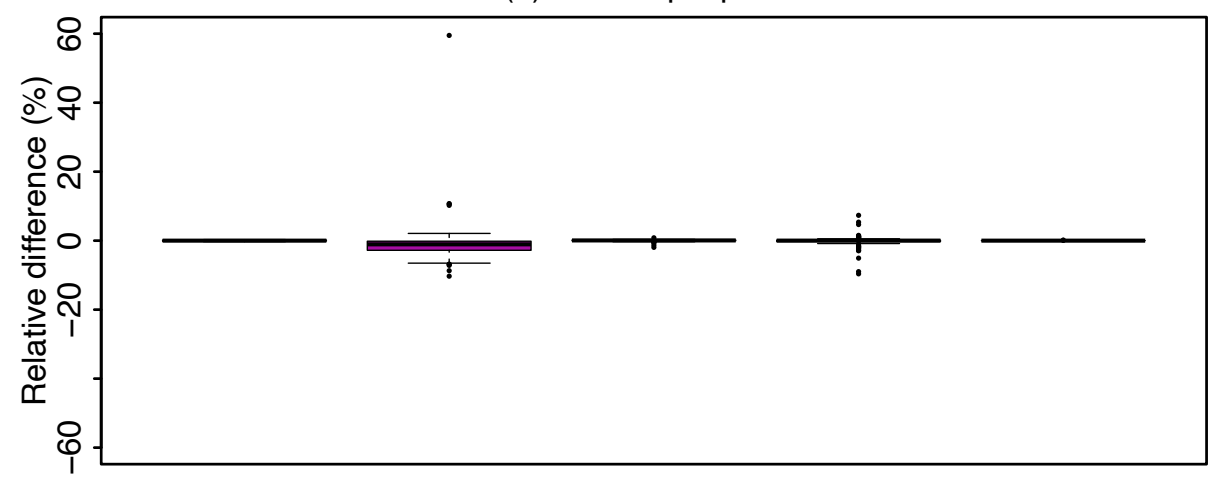

(c) Stratosphere

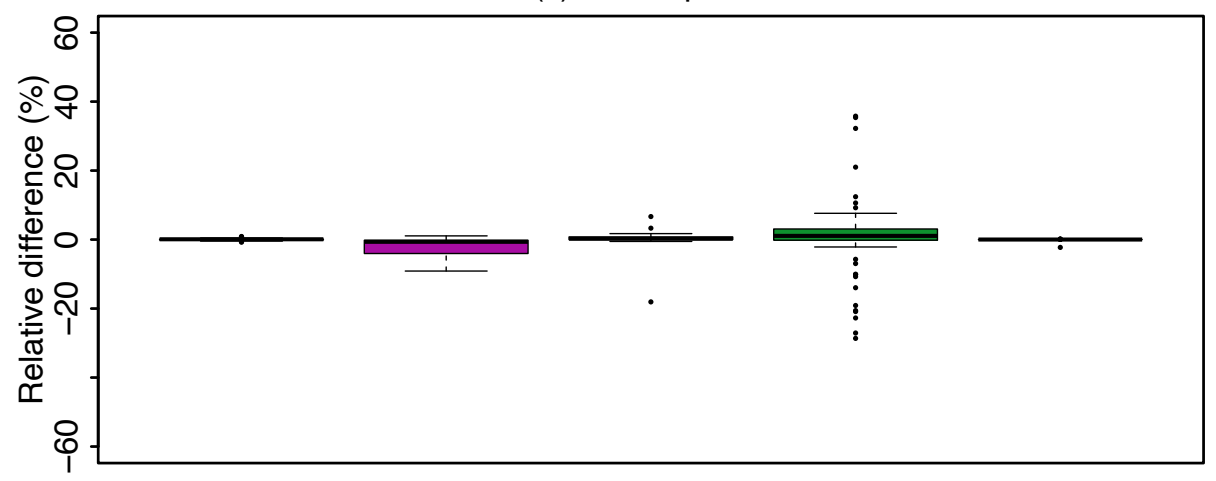

Fig. S5. The relative differences of atmospheric mass (averaged in the 8-year simulations) in the adaptive reduced chemistry mechanism for different species categories in the (a) boundary layer, (b) free troposphere, and (c) stratosphere. The top and bottom of each box are the 25th and 75th percentile, and the centerline is the 50th percentile. We use a threshold $\delta$ of 1500 molecules $\mathrm{cm}^{-3} \mathrm{~s}^{-1}$ to separate fast and slow species here. 
Relative differences of atmospheric masses for different species categories

(a) Boundary layer

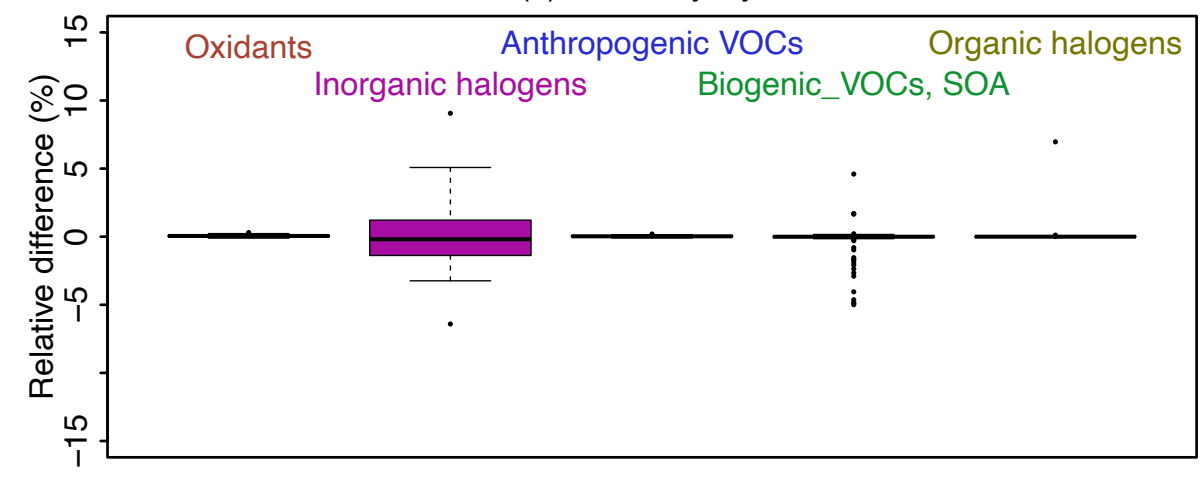

(b) Free troposphere

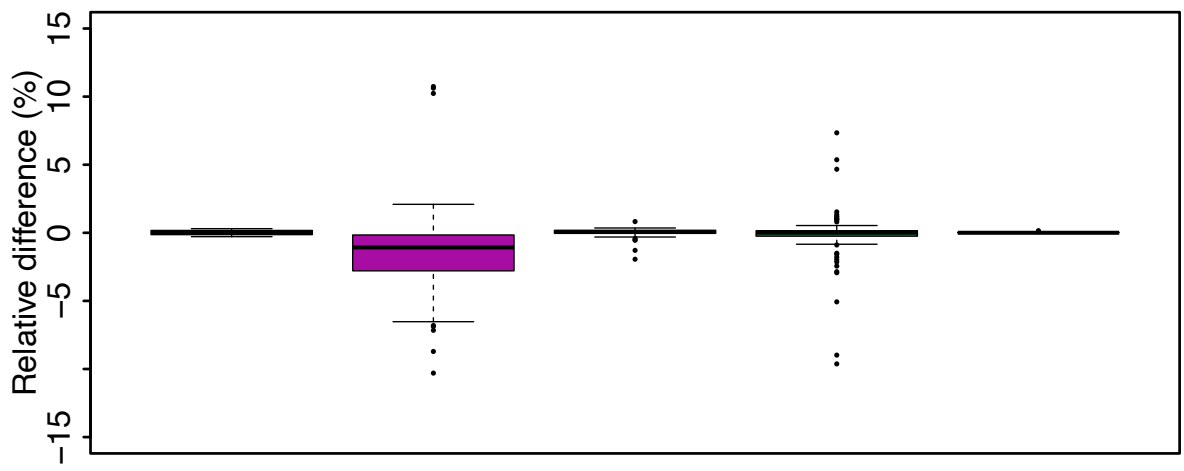

(c) Stratosphere

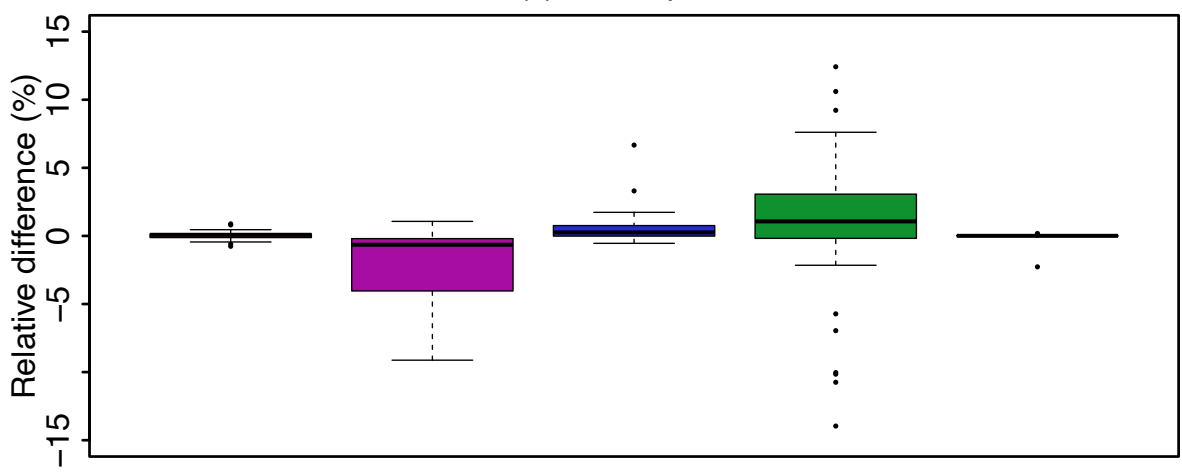

Fig. S6. Same as Fig. S5 but we present more details for the data from $-15 \%$ to $15 \%$. 
Relative differences of atmospheric masses over 8-year simulations $(\delta=1500)$

(a) Boundary layer

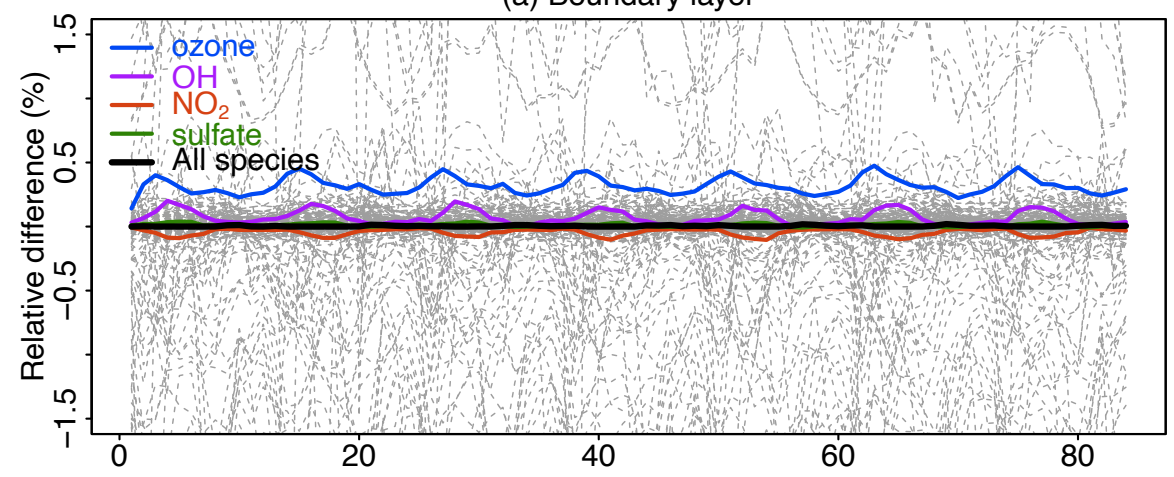

(b) Free troposphere

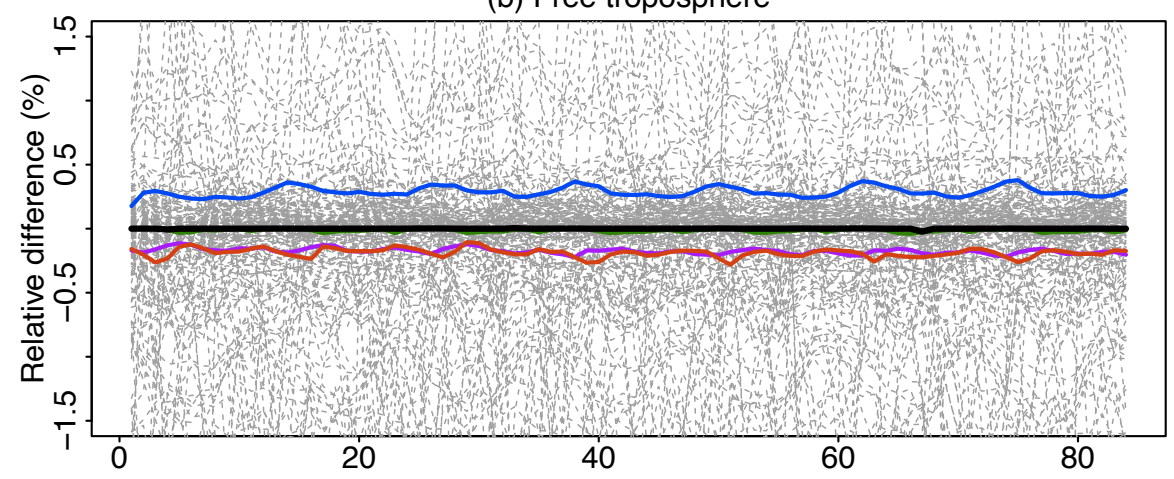

(c) Stratosphere

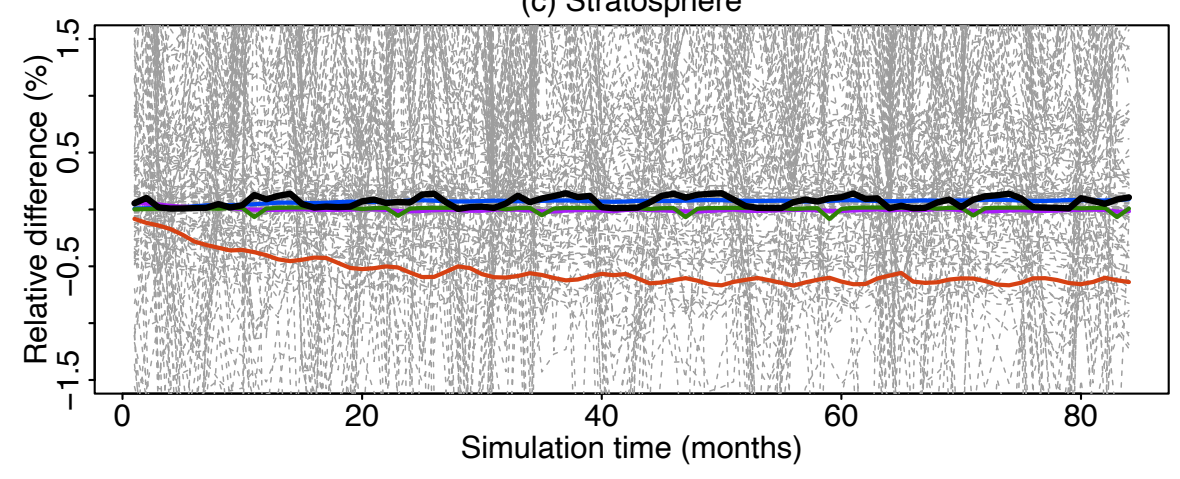

35 Fig. S7. Same as Figure 8 but for more details in the range between $-1.5 \%$ and $1.5 \%$. Results are also shown for the median relative difference across all species in the mechanism and more specifically for ozone, $\mathrm{OH}, \mathrm{NO}_{2}$, and sulfate. 


\section{Diagram for adding new species into the mechanism}

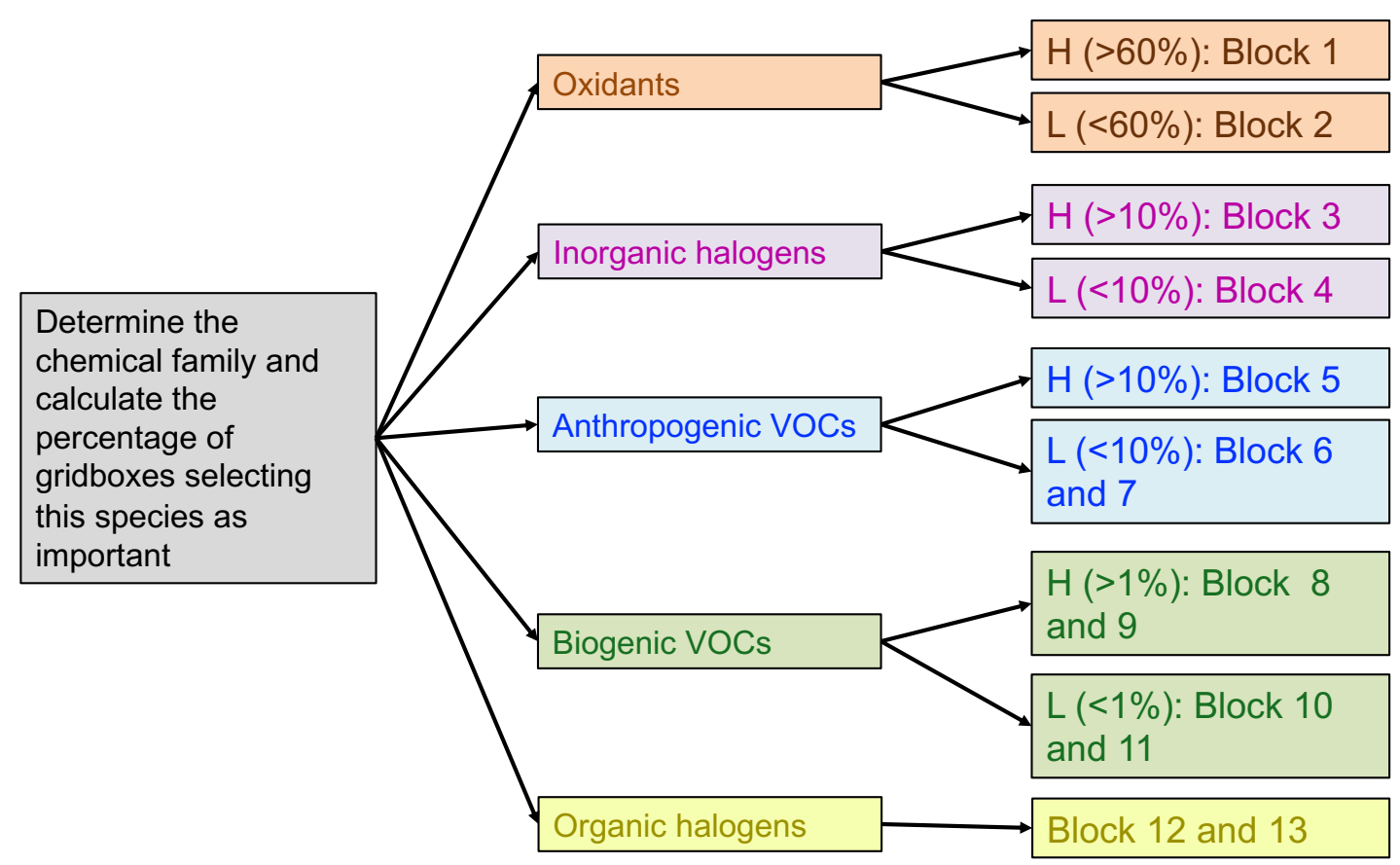

39 Fig. S8. Diagram of adding a new species to the mechanism. The location of the species is determined by its chemical family and the percentage of gridboxes (in parentheses in the last column) that select this species as fast. ' $\mathrm{H}$ ' ('L') means higher (lower) percentage of gridboxes that consider this species as fast. We use a threshold of 500 molecules $\mathrm{cm}^{-3} \mathrm{~s}^{-1}$ to partition fast and slow species. 
Table S1. Top 10\% Species with highest RRMSE and relative mass bias in the boundary layer, free troposphere and stratosphere*.

\begin{tabular}{|c|c|c|}
\hline & RRMSE & Relative mass bias \\
\hline Boundary layer & $\begin{array}{l}\text { I2O4, I2O2, I2O3, IBr, INO, ICl, IONO, OIO, } \\
\text { PRPN, HOI, BrSALC, BrSALA, ISNOHOO, } \\
\text { IONO2, ISNOOB, I2, PRN1, MAN2, } \\
\text { MACRN, MAOPO2, IO }\end{array}$ & $\begin{array}{l}\text { I2O2, I2O3, INO, TRO2, N, XRO2, Cl2O2, } \\
\text { IONO, OIO, PRPN, Br2, BrSALC, BrSALA, } \\
\text { ISNOHOO, IONO2, ISNOOB, I2, Cl2, } \\
\text { PRN1, MAN2, MACRN, MAOPO2 }\end{array}$ \\
\hline Free troposphere & $\begin{array}{l}\text { ISN1OG, I2O4, I2O2, I2O3, INO, ICl, OIO, } \\
\text { PRPN, BrSALA, MAOP, ISNOHOO, } \\
\text { ISNOOB, I2, PRN1, MAN2, ISNOOA, } \\
\text { MACRN, MAOPO2, I, IO, NMAO3, INO2 }\end{array}$ & $\begin{array}{l}\text { AERI, ISN1OG, I2O4, I2O2, I2O3, INO, HI, } \\
\text { IONO, OIO, HOI, BrSALC, BrSALA, } \\
\text { ISNOHOO, ISNOOB, I2, C12, PRN1, MAN2, } \\
\text { MACRN, I, IO, NMAO3 }\end{array}$ \\
\hline Stratosphere & $\begin{array}{l}\text { ISN1OA, ISN1OG, LVOC, PMNN, MRP, } \\
\text { IPMN, MACRNO2, MONITS, GAOO, } \\
\text { MVKN, MGLYOO, GLYX, MGLOO, } \\
\text { MAN2, MACRN, HCOOH, KO2, MGLY, } \\
\text { RIO2, INO2, MRO2 }\end{array}$ & $\begin{array}{l}\text { ISN1OA, ISN1OG, DHDC, PRPN, } \\
\text { DHPCARP, ISNOHOO, ISNOOB, INPN, I2, } \\
\text { PRN1, PROPNN, MAN2, ISNOOA, } \\
\text { MACRN, MAOPO2, OLND, OLNN, KO2, } \\
\text { NMAO3, ISN1, RIO2, INO2 }\end{array}$ \\
\hline
\end{tabular}

${ }^{*}$ The full GEOS-Chem mechanism has 228 species. The full names of these acronyms can be found at http://wiki.seas.harvard.edu/geos-chem/index.php/Species_in_GEOS-Chem. 